\title{
Research Paper: Persian Translation and Psychometric Properties Assessment of Self-Determination Student Scale for Adolescents
}

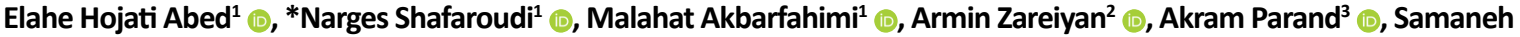 \\ Karamali Esmaili ${ }^{1}$
}

1. Department of Occupational Therapy, School of Rehabilitation Sciences, Iran University of Medical Sciences, Tehran, Iran. 2. Department of Health in Disaster and Emergencies, Faculty of Nursing, AJA University of Medical Sciences, Tehran, Iran. 3. Department of Psychology, Faculty of Psychology and Education, University of Tehran, Tehran, Iran.

\begin{tabular}{|l|l}
$\begin{array}{c}\text { Use your device to scan } \\
\text { and read the article online }\end{array}$ \\
Pstehtion Hojati Abed E, Shafaroudi N, Akbarfahimi M, Zareiyan A, Parand A, Karamali Esmaili S. [Persian Translation and \\
2020; 20(4):350-359. http://dx.doi.org/10.32598/rj.20.4.350 \\
doi http://dx.doi.org/10.32598/rj.20.4.350
\end{tabular}

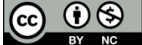

Received: 13 Jun 2019 Accepted: 25 Oct 2019 Available Online: 01 Jan 2020

Keywords: Self-determination, Psychometrics, Adolescents, Validity, Reliability

\begin{abstract}
Objective Self-determination is the ability of recognizing, setting and achieving goals based on knowledge and self-assessment. This ability is essential for the healthy development of adolescents. Self-determination is influenced by knowledge, skills, beliefs, and contextual factors that exist in one's living environment. Since it is an essential element for having a successful life, its assessment and related skills are also important; however, there is no assessment tool for its measurement in Iranian population. The aim of this study was to translate the Self-Determination Student Scale (SSDS) into Persian and determine its psychometric properties including face, content, and construct validity as well as internal consistency and test-retest reliability in adolescents aged $14-18$ years.

Materials \& Methods In this methodological study, the SSDS was translated into Persian to be used on Iranian population and validated according to the International Quality of Life Assessment (IQOLA) protocol. Samples were 498 high school students (mean age $=15.15 \pm 0.9 ; 227$ females and 221 males) who were selected using convenience sampling technique with maximum diversity in Tehran. They were divided into two groups of with and without emotional/behavioral symptoms using the Youth Self-Report tool. The face validity of the translated SSDS was determined based on the opinions of samples and experts. The Content Validity Index (CVI) and Content Validity Ratio (CVR) were also calculated for each items of the translated version. The construct validity was tested by comparing known groups (gender groups and groups at risk of emotional/behavioral disorders). Moreover, its internal consistency was estimated by Kuder-Richardson formula, and test-retest reliability was tested using Intraclass Correlation Coefficient (ICC) on 16 students with a time interval of 14 days.

Results In the Persian version of SDSS, 4 items were removed from the original version. After confirmation of its face validity after modification, it was found that its items had appropriate content validity based on CVI and CVR scores. The mean of self-determination score under all subscales and most of items was significant between the gender group and the group at risk of emotional/behavioral disorders $(P<0.001)$. The Kuder-Richardson coefficient was obtained 0.89 and for five subscales, it was in a range of 0.51 to 0.72 . The ICC $(0.98 ; 95 \% \mathrm{Cl}: 0.95$ to 0.98$)$ approved the good reliability of the instrument.

Conclusion The Persian version of SDSS had good validity (face, content, and construct) and reliability after testing it on the high school students. Therefore, it can be used in clinical and research studies to assess the self-determination of students. Considering the importance of self-definition in adolescence, there is a need for further studies using the SDSS to highlight the potential problems of high school students in self-determination and designing related training programs.
\end{abstract}

* Corresponding Author:

Narges Shafaroudi, PhD.

Address: Department of Occupational Therapy, School of Rehabilitation Sciences, Iran University of Medical Sciences, Tehran, Iran.

Tel: +98 (21) 22227124

E-Mail: shafarodi.n@iums.ac.ir 


\title{
ترجمه و تعيين ويزُّى هاى روانسنجى ((مقياس خودتعيينترى دانشآموز)) در نوجوانان؛نسخه فارسى
}

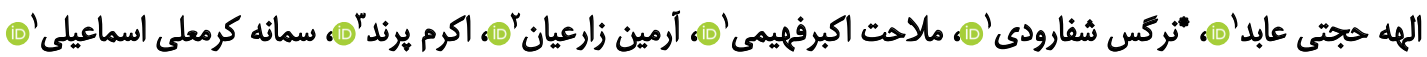

ا. ا. تروه كاردرمانى، انشكده علوم توانبخشى، دانشعاه علوم يزشكى ايران، تهران، ايران.

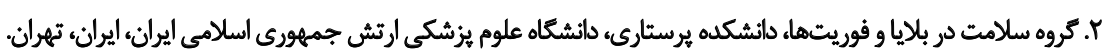

ب. ب. كروه روانشناسى، دانشكده روانشناسى و علوم تربيتى، دانشكاه تهران، تهران، ايران.

\section{حكSد}

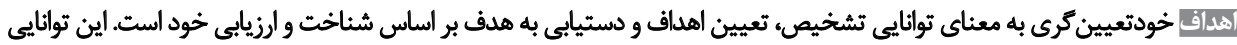

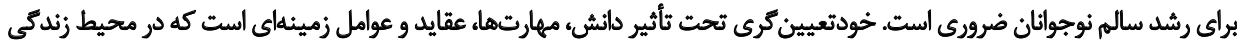

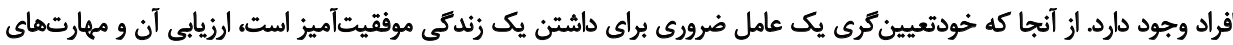

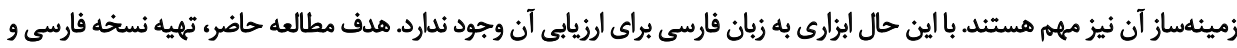

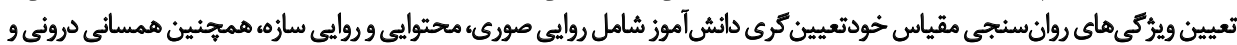

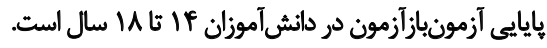

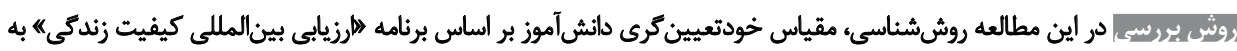

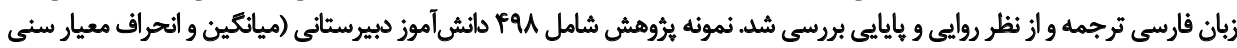

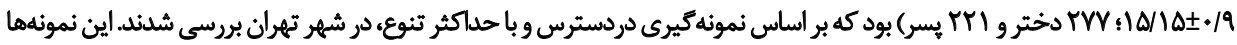

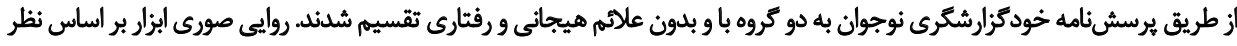

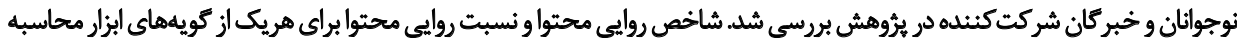

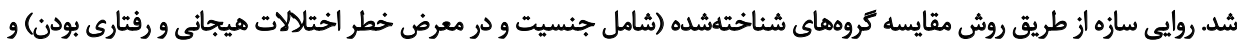

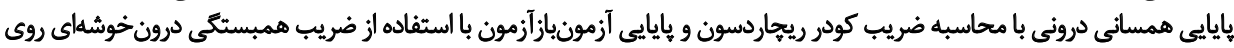

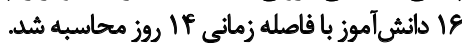

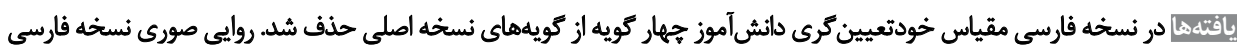

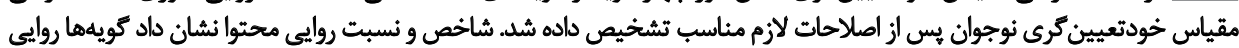

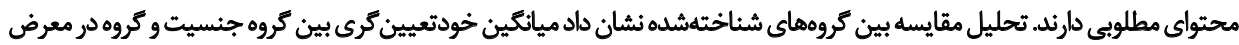

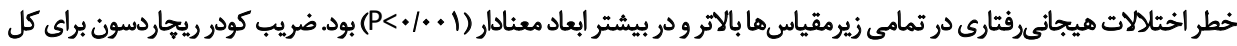

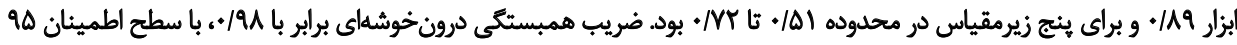

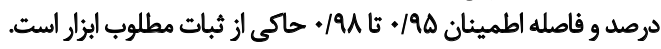

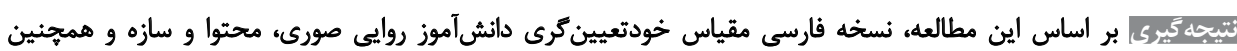

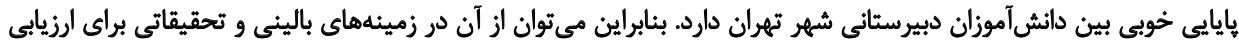

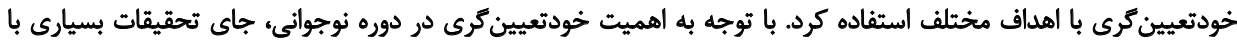

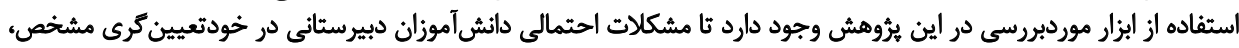

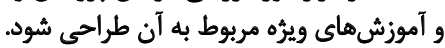

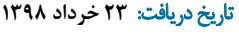

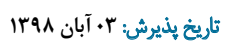

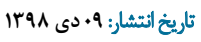

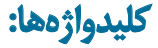

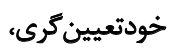

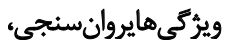
نوجوانان، روايیى، هايايى 
مداخله آموزشى مي توان اثربخشى مداخله را بررسى كرد يا به يه مقلمه

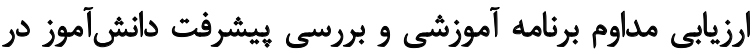

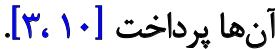

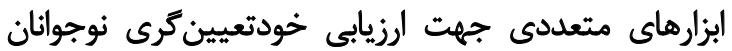

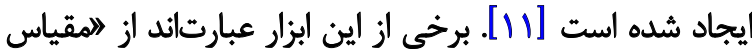

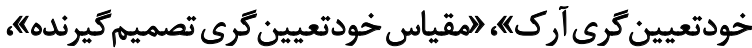

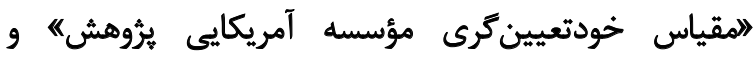

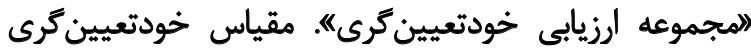

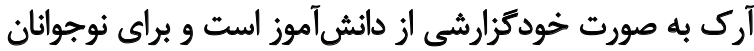

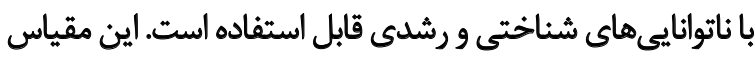

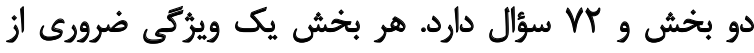

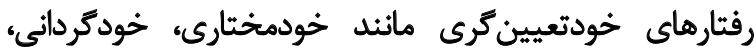

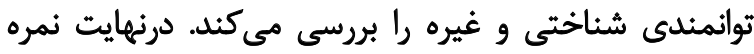

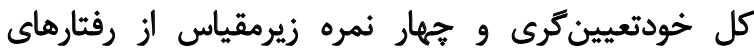

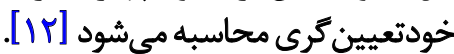

"مقياس خودتعيين كرى تصميمكيرنده يك ئ مقياس

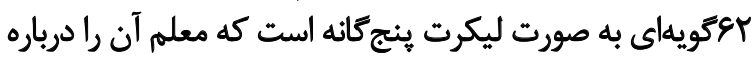

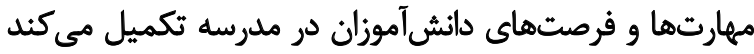

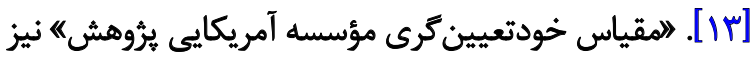

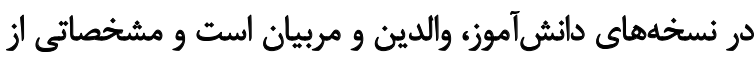

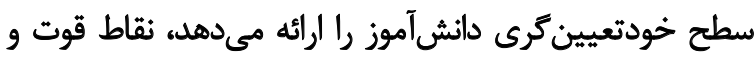

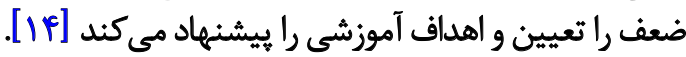

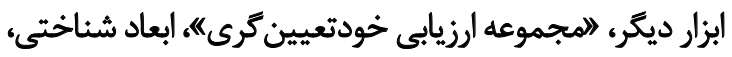

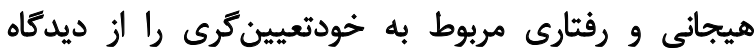

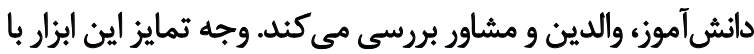

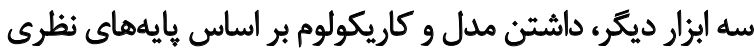

مدل خودتعيين كرى فيلد و هافمن است ماريكول [1ه]

اين مدل بر متغيرهاى مرتبط با خودتعيين كرى متمركز است؛

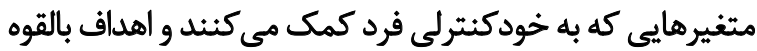

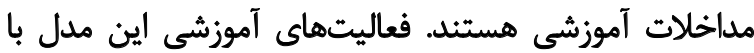

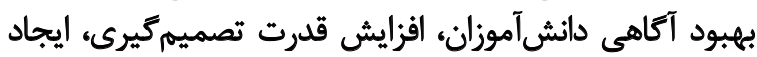

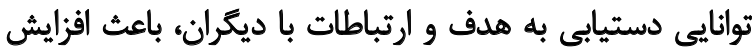

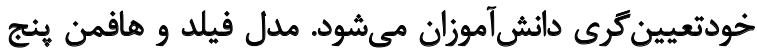

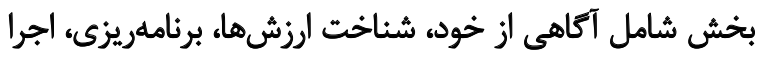

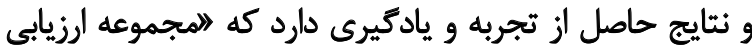

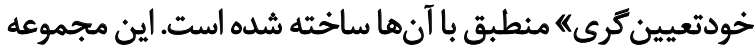

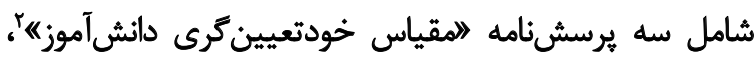

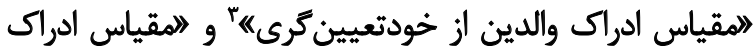

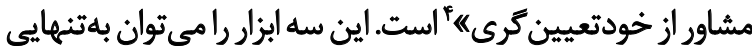

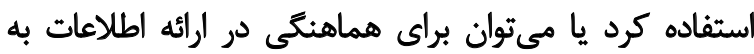

نوجوانى كذر از وابستكى دوران كودكى به سوى استقلال يا

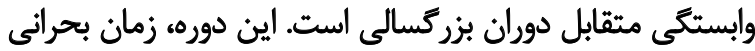

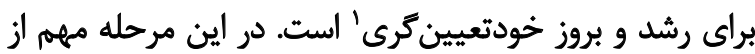

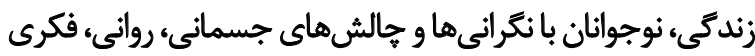

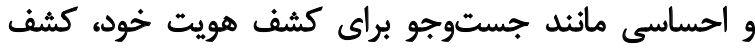

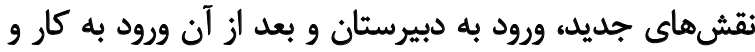

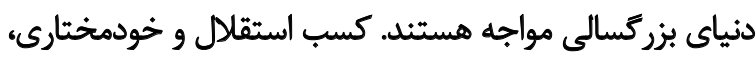

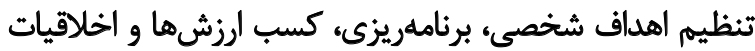

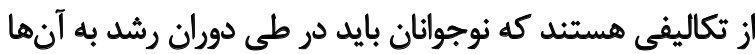

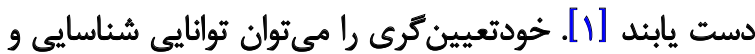

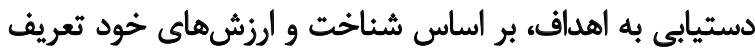

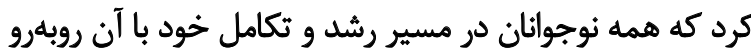

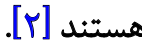

امروزه خودتعيينگرى، توجه زمينههاى مختلفى همجون

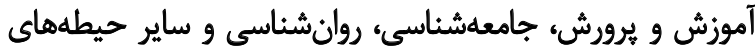

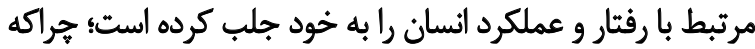

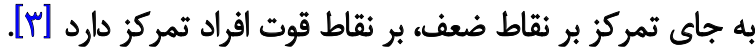

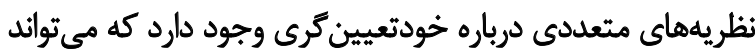

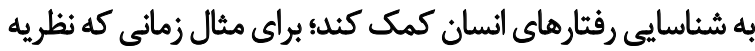

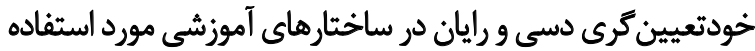

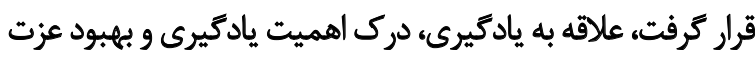

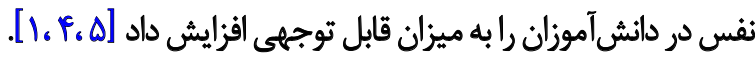
خودتعيين گرى نقشى مهم و حياتى در دوره نوجوانى دارد.

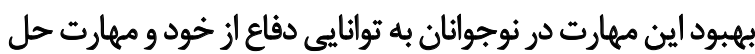

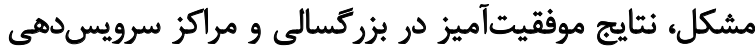

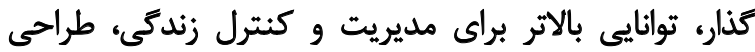

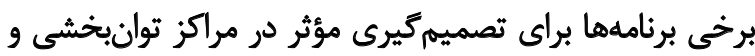

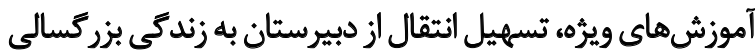

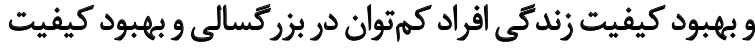

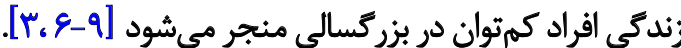

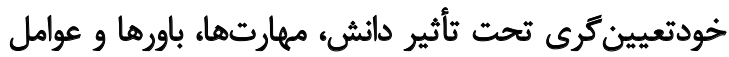

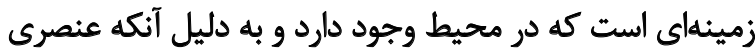

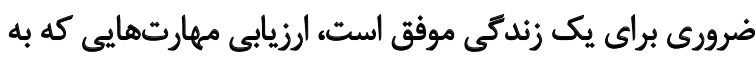

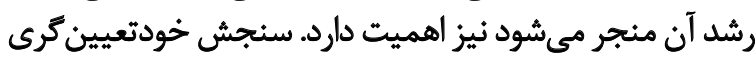

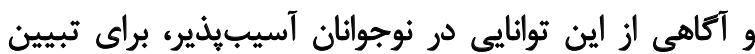

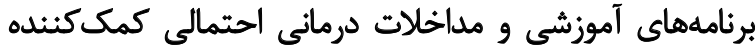

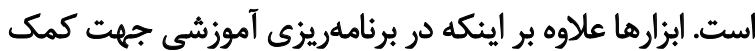

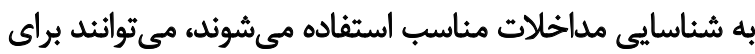

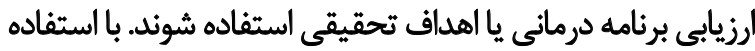

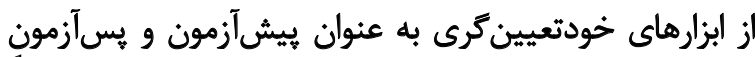

1. Self-determination 
تكاملى اصلى مقياس خودنتعيين كرى دانش آموز قابليت اطمينان و

تكراريذيرى در نسخه فارسى دارد؟

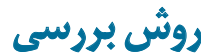

جامعه مورديروبس

اين مطالعه، يك مطالعه روش شناسى با هدف اعتباريابى ابزار

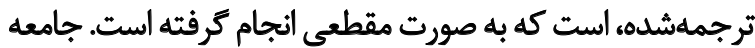

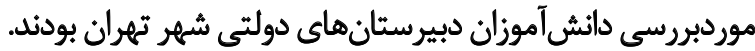

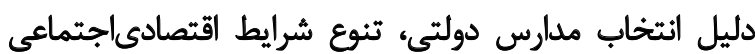

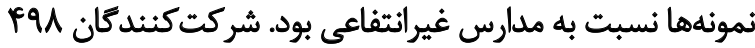

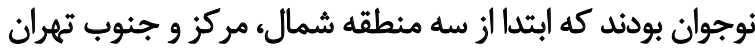
و از مدارس واجد شرايط انتخاب شدند.

در هر منطقه به صورت تصادفى سه مدرسه و در هر مدرسه

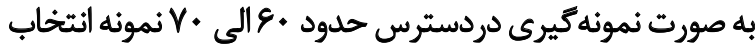

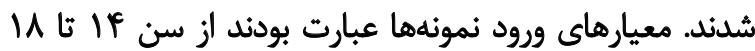

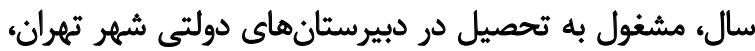

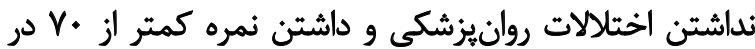

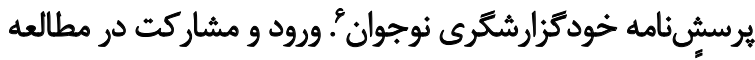

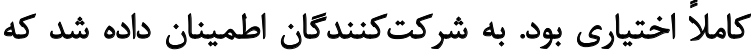

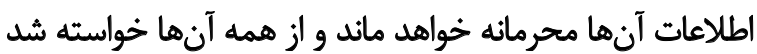

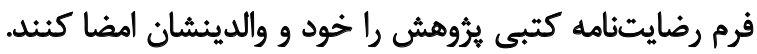

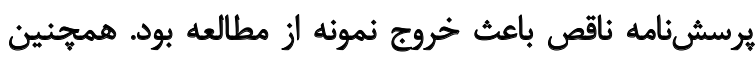

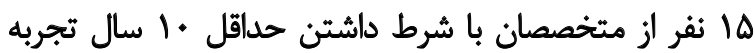

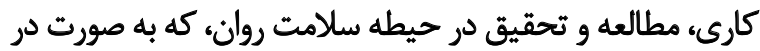

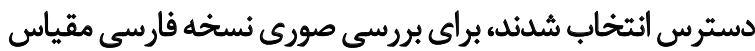

خودتعيين كرى دانشآموز با اين يُروهش همكارى داشتندي

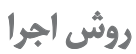

مرحله اول انجام اين يروهش، فرايند ترجمه و تريهيه نسخه

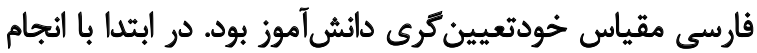

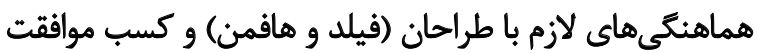

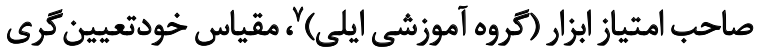

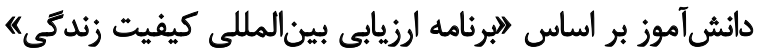

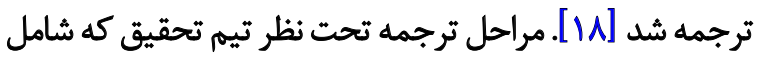

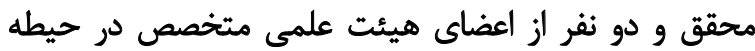

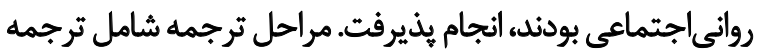

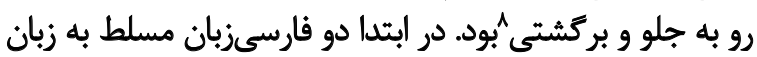

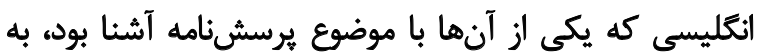

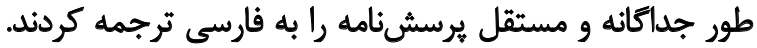

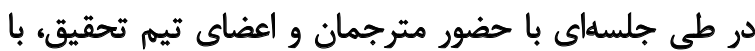

6. Youth Self-Report (YSR)

7. Ealy education group

8. Backward-forward
دانش آموز اين سه ابزار را همراه با هم به افرادى همجيون والدين،

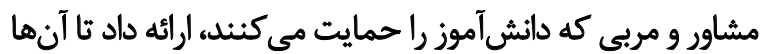

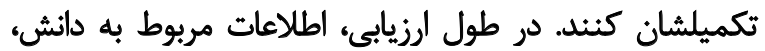

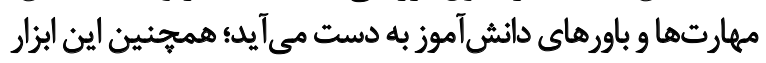

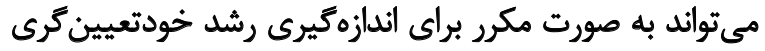
دانش آموزان در طى يك دوره زمانى به كار رود [هان]

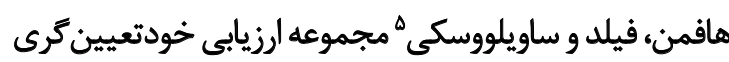

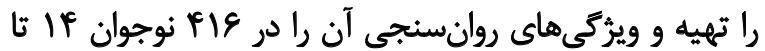

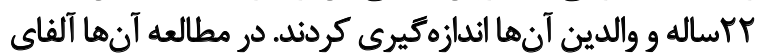

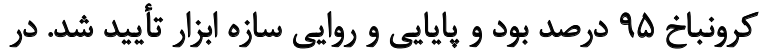

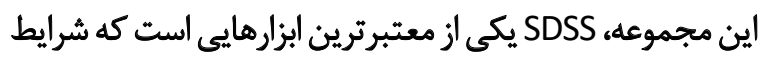

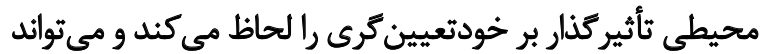

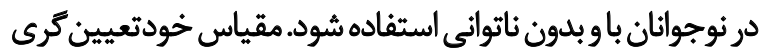

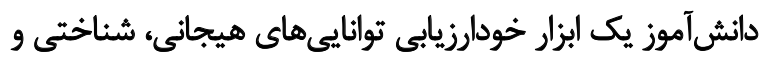

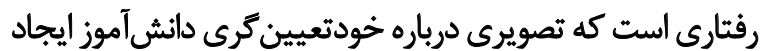

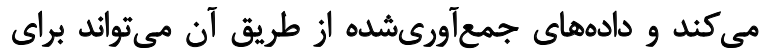

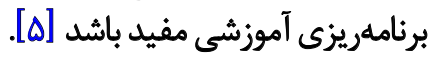
الامرى يكنسخه عربى ازفرم كوتاهشدهمقياس خودتعيين كرى دئ

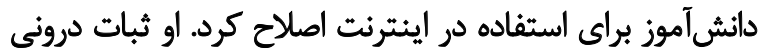

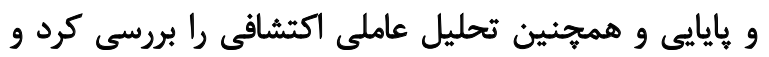

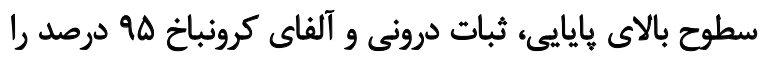

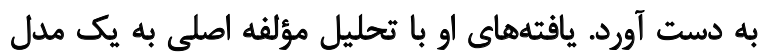

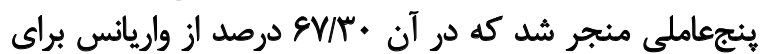

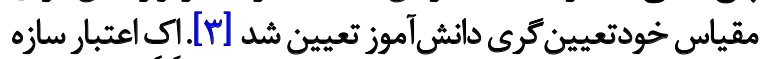

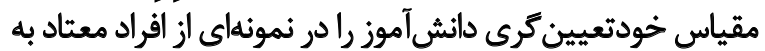

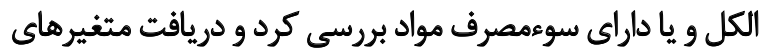
جمعيتشناختى شامل جنسيت، نزاد، تحصيلات و و سن روني

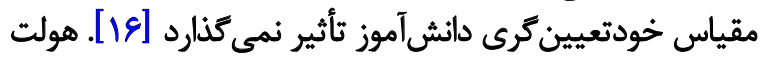

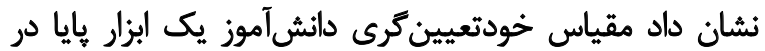

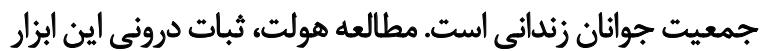

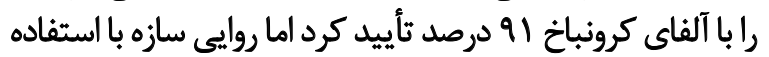

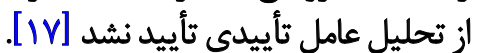

خودتعيين كرى در دوره نوجوانى اهميت فوقالعادماي دارد؛

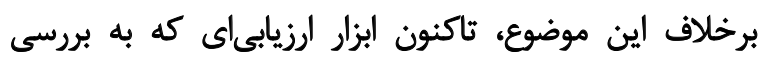

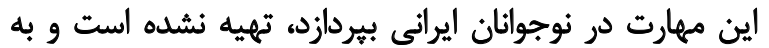

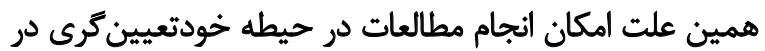

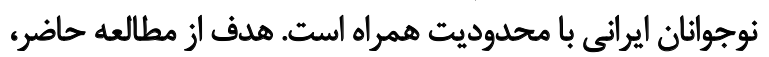

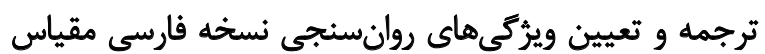

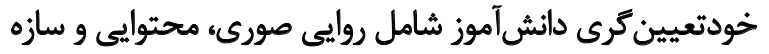

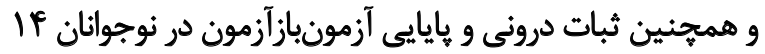

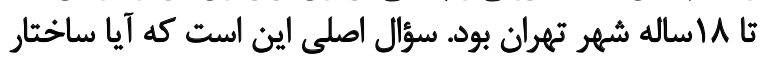




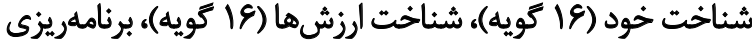

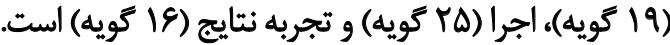
اين مقياس در انتها براي هر زيرمقياس يك نمرهو يك نمره كلى

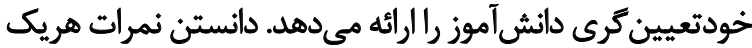

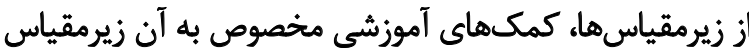

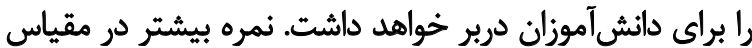

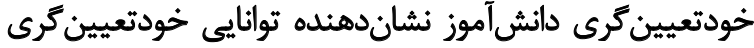
بيشتر است. زمان تكميل برسش

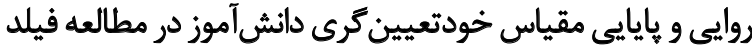

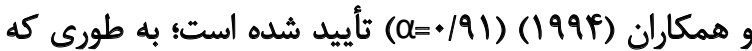

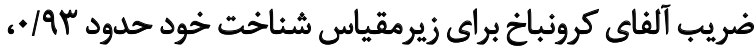

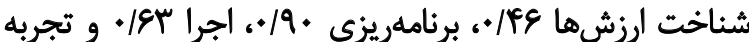

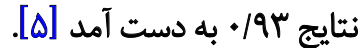

\section{يرسشنامه خودَّزارشكَرى نوجوان}

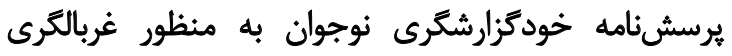

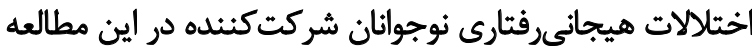

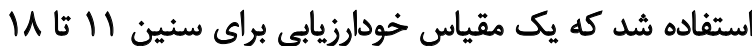

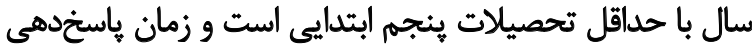

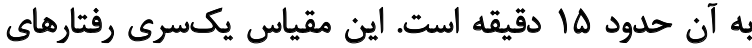

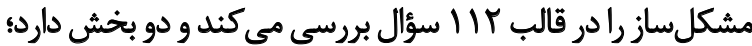

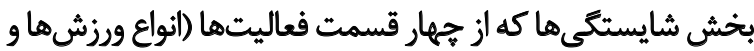

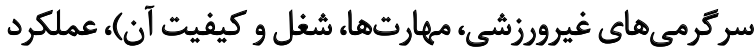

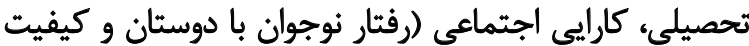

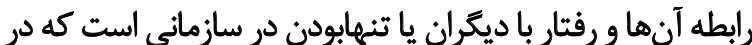
آن عضويت دارد) و شايستكى كلى تشكيل شده است

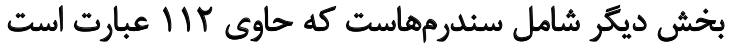

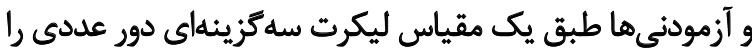

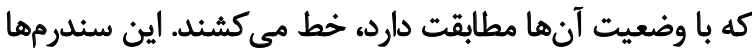

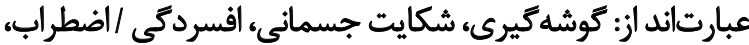

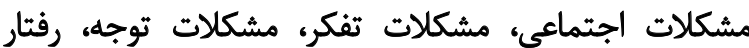

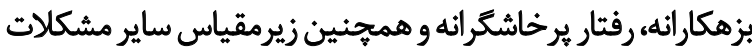

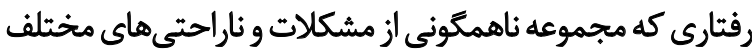

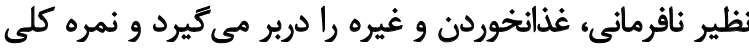

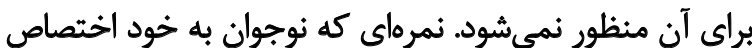

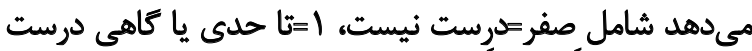

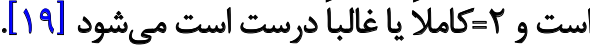

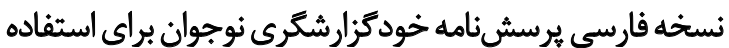

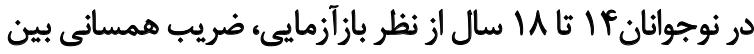

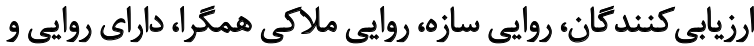

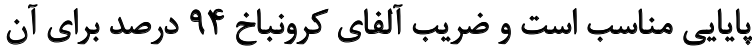

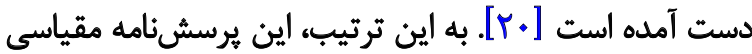

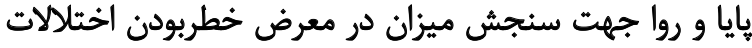

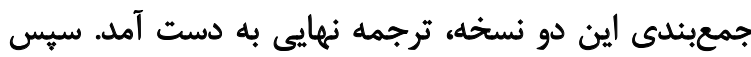

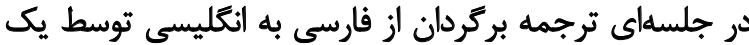

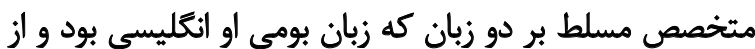

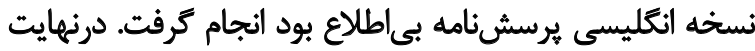

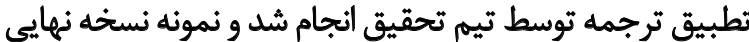

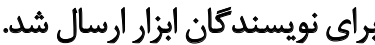

جهت بررسى روايى صورى و محتوايى ابزار به ترتيب، مصاحبه

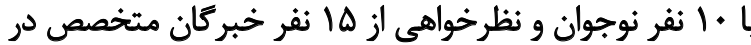

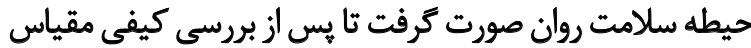

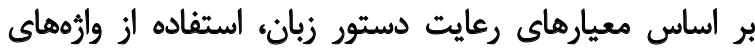

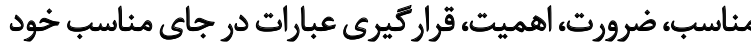

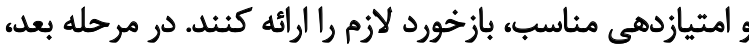

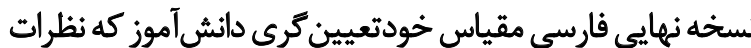

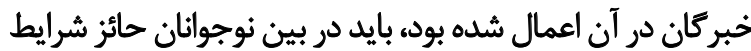
ورود به يُروهش توزيع مى دراند.

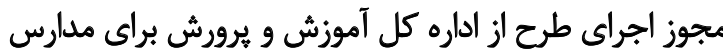

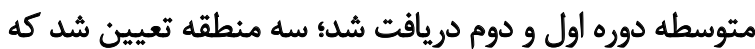

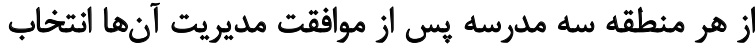

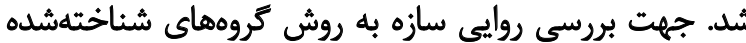

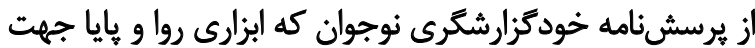

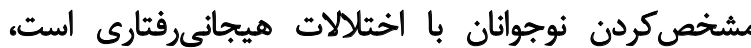

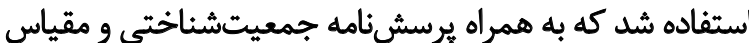

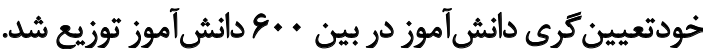

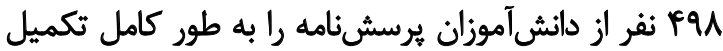

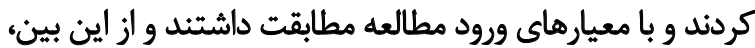

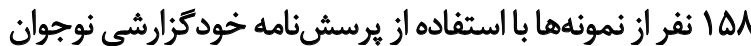

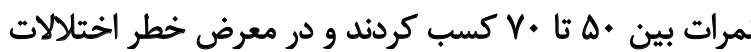

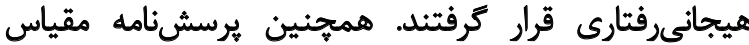

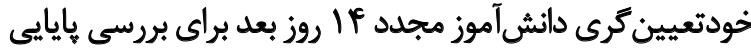

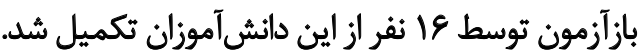

\section{مقياس خودتعيين كرى دانش آموز}

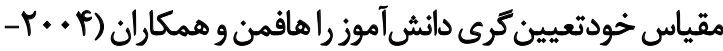

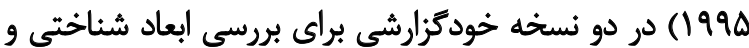

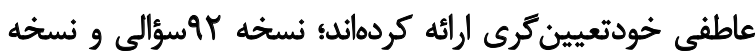

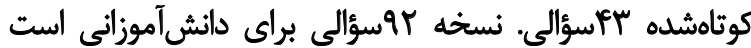

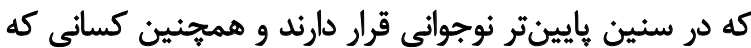

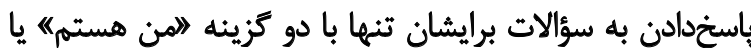

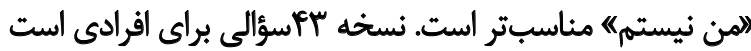

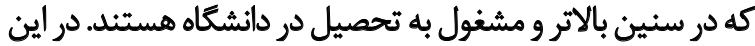

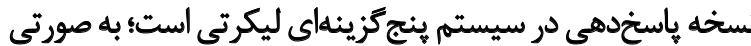

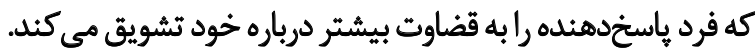

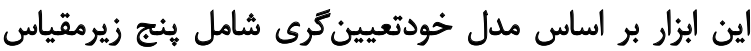




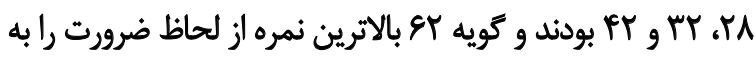

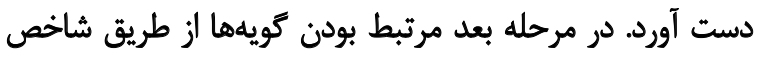

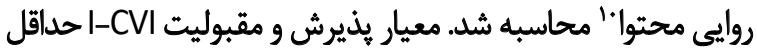

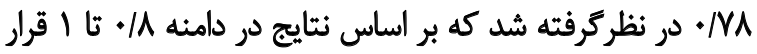

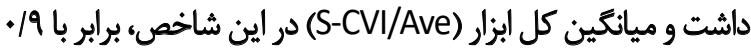

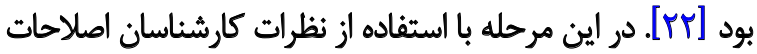

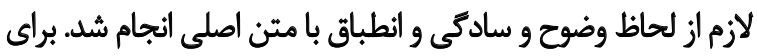

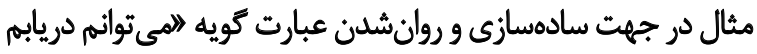

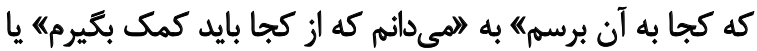

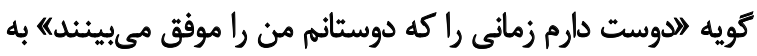

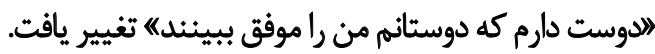

براى سنجش روايى سازه، از مقايسه گروهماي شناختهشده

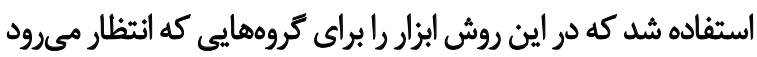

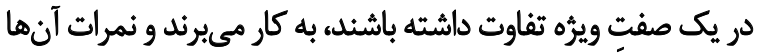

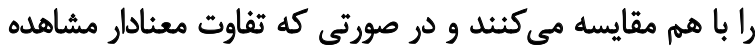

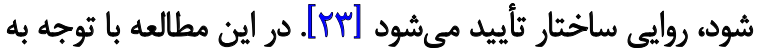

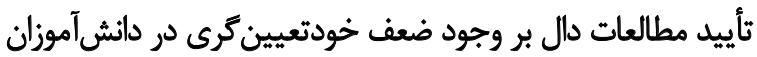

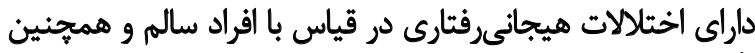

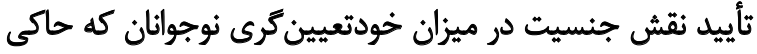

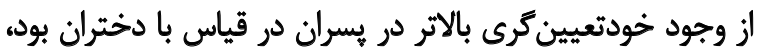

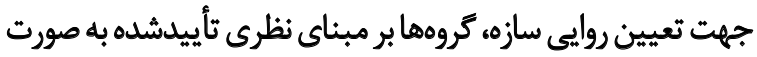

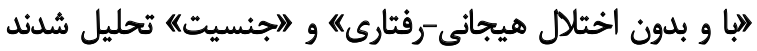

.[YF-YA]

ونتايج اين تحليل نشان داد هريك از زيرمقياس هاى خودتعيين كرى

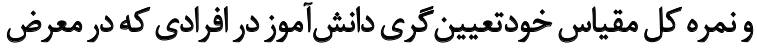

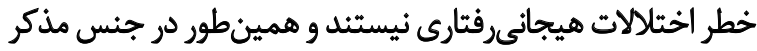

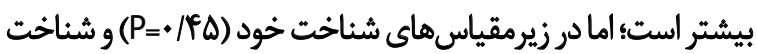

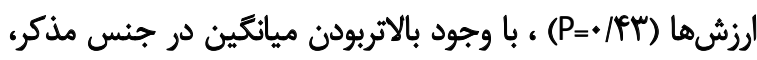

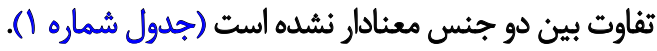
إيايايى نسخه فارسى مقياس خودتعيين گرى دانشآموز با استفاده

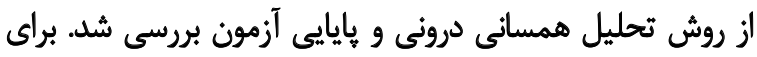

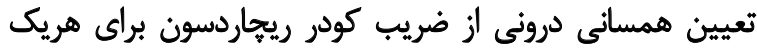

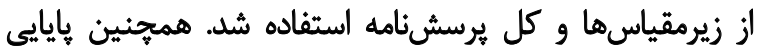

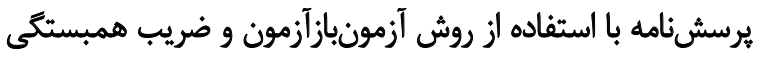
درون يوشهاي با فاصله دو هفته محاسبه شده است.

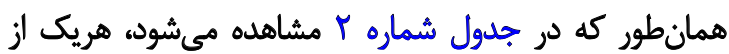

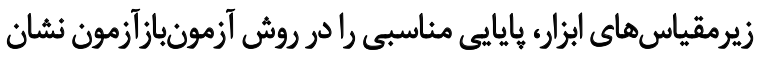

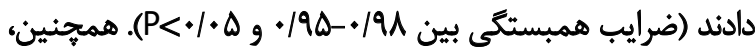

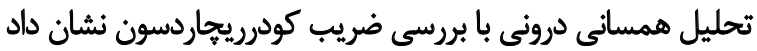

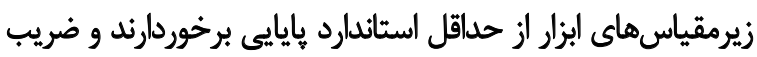

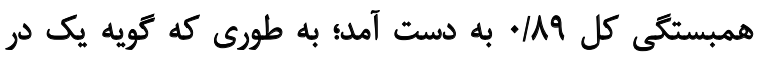

هيجانىرفتارى در دانشآموزان است. اكر نمرات كسبشده

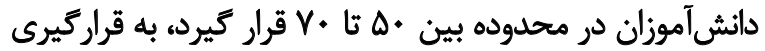

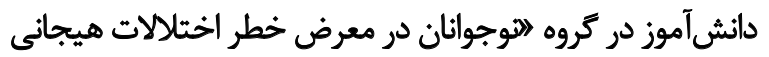

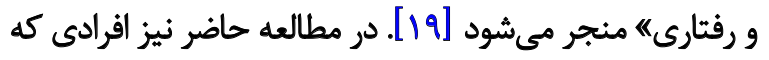

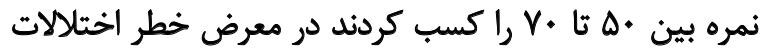

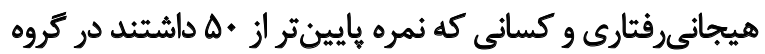

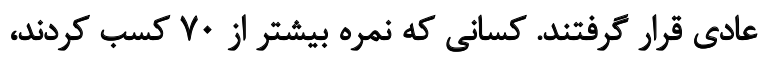

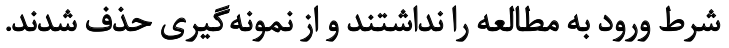

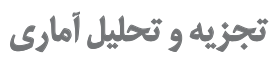

جهت تحليل آمارهاى توصيفى از شاخصهاى آمارى ميانكين

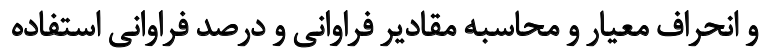
شد. براى بررسى روايى مقياس از روايى صورى و و محتوايى و و ورائي

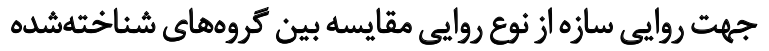

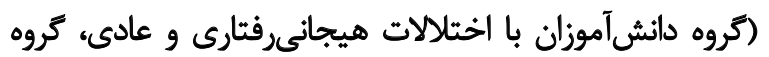

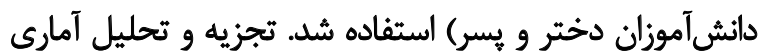

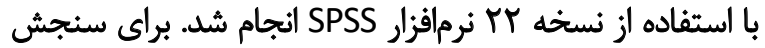

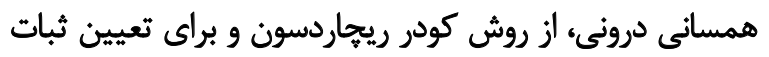

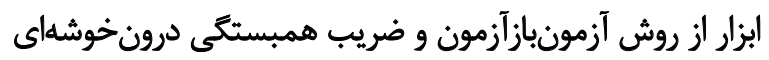

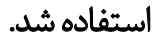

ياقتههها در اين مطالعه FqA نوجوان با ميانتين سنى و انحراف معيار

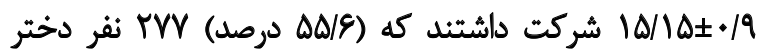

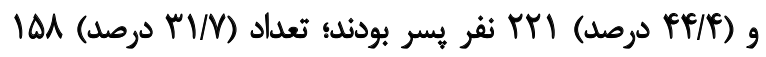

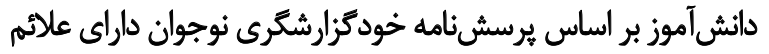

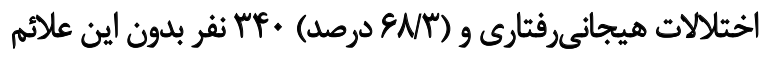

در بررسى روايى صورى، براى ارزيابى وضوح و درك دانشآموزان

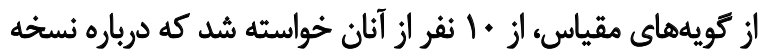

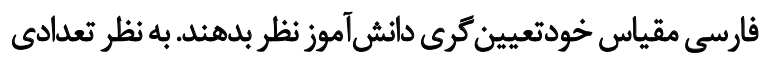

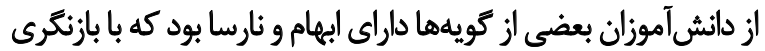

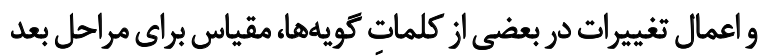

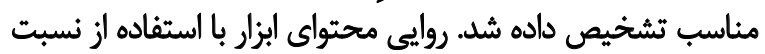

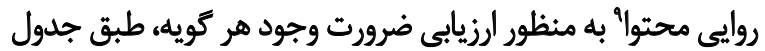

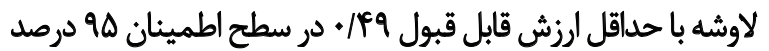

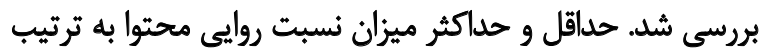

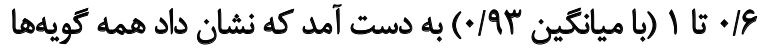

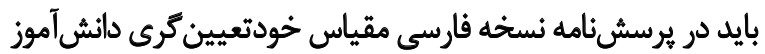

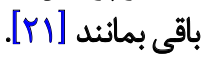

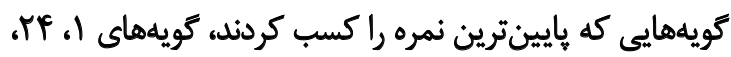


جدول ا. شاخصهاي آمارى گروههاى شناختهشده دانش آموزان در روايى سازه با فاصله اطمينان ه9 درصد

\begin{tabular}{|c|c|c|c|c|c|c|}
\hline \multirow[b]{2}{*}{$\mathbf{P}$} & \multicolumn{2}{|c|}{ هيانكين |انحراف معيار } & \multirow[b]{2}{*}{$\mathbf{P}$} & \multicolumn{2}{|c|}{ مياتكين||نراف معيار } & \multirow[b]{2}{*}{ متغيرها } \\
\hline & بـر & مختر & & هيجانئرفاتارى & هيجانمىرفتارى & \\
\hline.$/ \% \Delta$ & YNVIET/M & TV/৭৭ะY/AT & $<\cdot 1 \cdot+1$ & $r q \pm r / \cdot r$ & $r E / I Y \pm Y / N Y$ & شناخت خود \\
\hline . & TW/AIV/AY & rg/ArIT/rq & $<* 1 \cdot .1$ & WVNEIVISE & $r \Delta / / Y \pm T / N$ & شناخت ارزشها \\
\hline$<\cdot 1 \cdot .1$ & re/lq土т/Fq & $\mu \in / r Y \pm r / r \Lambda$ & $<+1 .+1$ & $r g / 19 \pm r / r q$ & $r I / Y \Delta \pm Y / M^{E}$ & برنامهريزى \\
\hline$<\cdot \mid \cdot .1$ & $r T / \Delta Q \pm T / T$ & $\varphi+/ r V \pm r / Q$ & $<\cdot 1 \cdot+1$ & $F r / F q \pm r / /$ & $\Pi \nabla / \Psi \nabla \pm \Psi /+\Delta$ & اجرا \\
\hline .1 .0 & TAYTIT/NQ & TV/VEIY/AT & $<+1 *+1$ & rNQI \pm V/R & $\Gamma \Delta / q Y \pm T / T q$ & تجربه نتايج و يادكيرى \\
\hline$<\cdot \mid \cdot .1$ & $\mid 8 T / R \pm Q / r$ & $|\Delta V / T Y \pm I|$ /QV & $<+1 \cdot+1$ & $|A \times| \Delta \& \pm N||$ & $\mid E F / T \cdot \pm N T Y$ & كل \\
\hline
\end{tabular}

جدول Y. همسانى درونى و همبستى درونخوشهاى زيرمقياس هاى مقياس خودتعيين كرى دانشآموز

\begin{tabular}{|c|c|c|c|c|}
\hline تعداد كويهها & فاصله اطمينان & ضريب همبستكى درون خوشهاى & ضريب كودر ريعاردسون & عامل \\
\hline 18 & $. / 99-. / 98$ &.$/ 4 \mathrm{~A}$ &.$|9|$ & شئاخت خود \\
\hline 18 & $. / 41-. / 14$ &.$/ 9 \Delta$ & $. / \Delta \mid$ & شناخت الرزشها \\
\hline r. & $. / 99-. / 94$ &.$/ 94$ & $\cdot / \pi$ & برنامهريزى \\
\hline m & $. / 99-. / 91$ & +/ar & $\cdot / \pi$ & اجرا \\
\hline 18 & $. / 4-+/ 9)$ & the & .18. & تجربه ثتايج و يادكيرى \\
\hline qr & $. / 99-+/ 98$ &.$/ 4$ &.$/ 19$ & كل \\
\hline
\end{tabular}

توانبخننى

كار گرفته شده است. بعضى گويههاى نسخه فارسى مانند كويههاى

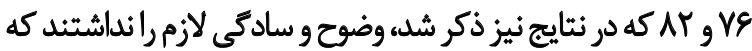

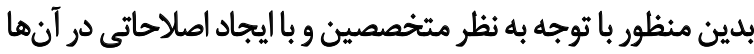
تغييراتى در جهت روانسازى عبارت براى دانشآموزان انجام شدادي

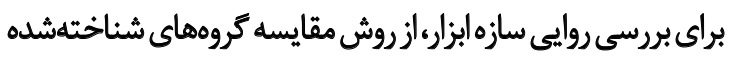

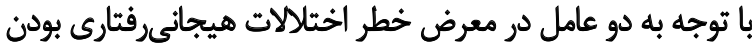

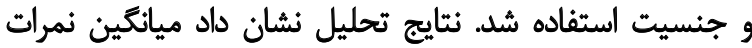

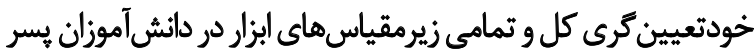

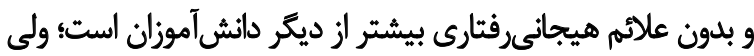

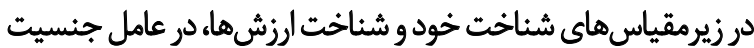
باوجود اختلاف ميانكين، تفاوت معنادارى حاصل نشده است

همانطور كه نتايج تحقيقات كارتبر و همكاران و وكلى نشان

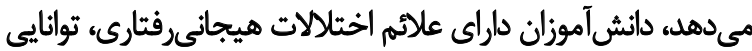

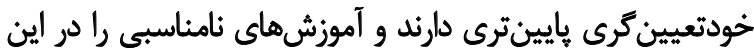

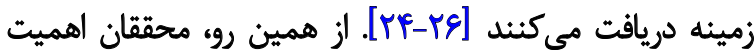

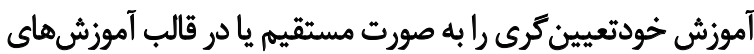

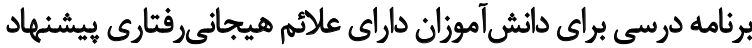

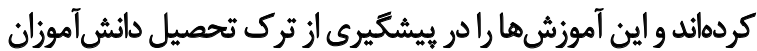

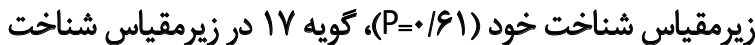

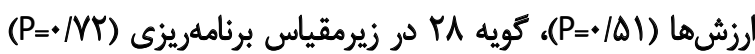

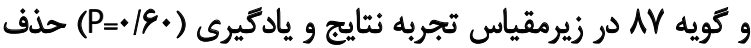
شند ث

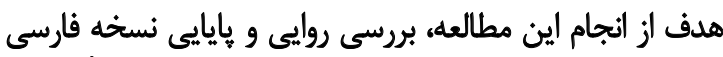

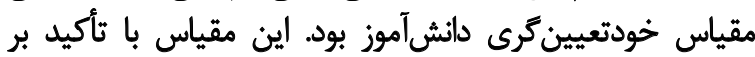

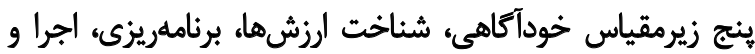

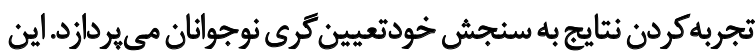

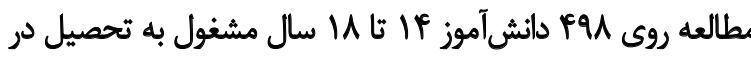

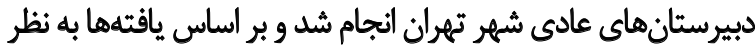

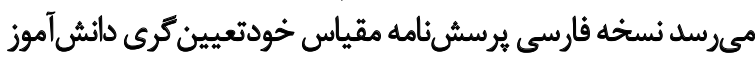
در نوجوانان فارسىزبان، روايى و بايايى قابل قبولئلى دارد.

همان كونه كه نتايج نشان ميدهده در حالى كه ميزان قابل قبول

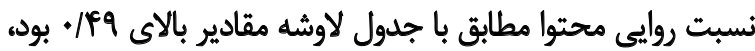

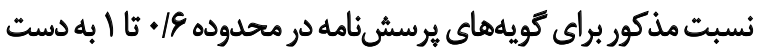

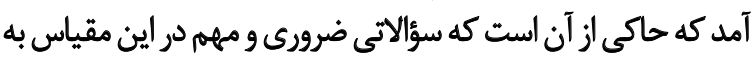


خودتعيين كرى دانش آموزان در قبل و بعد از مداخلات، يا بررسى ارتباط خودتعيين خرى با متغيرهاى مورد سؤال استفاده شود.

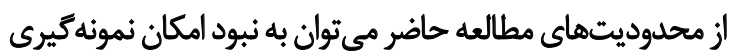

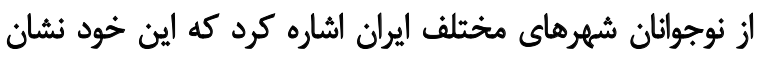

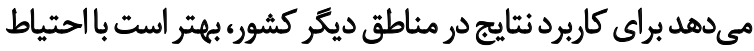

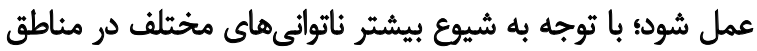

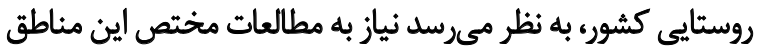

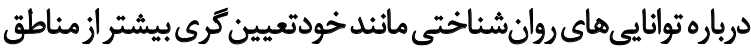

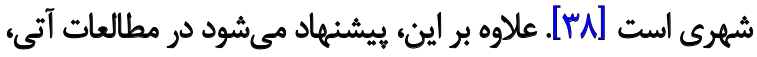

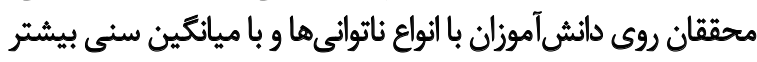

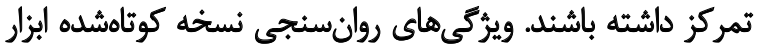

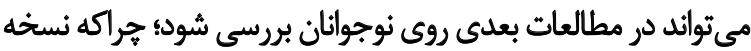

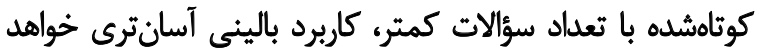
داشت.

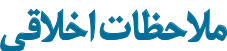

\section{يبيروى أز اصول اخلاث بؤوهش}

كد اخلاق اين مقاله از دانشكاه علوم يزشكى ايران به شماره (9321525001/R.IUMS.REC.1396)، صادر شده است.

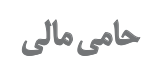

ايـن يُروهـش بخشى از بايان نامه دكترى تخصصى كاردرمانى

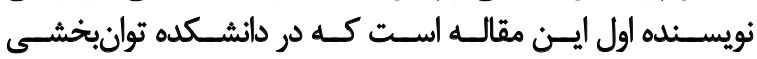

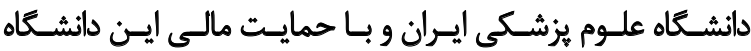

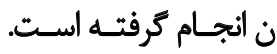

$$
\text { مشاركتويسندكًان }
$$

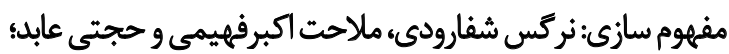

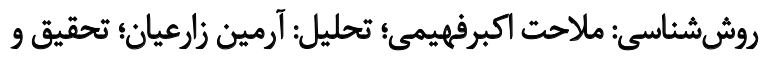

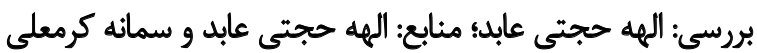

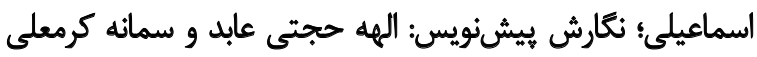

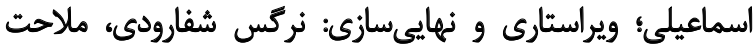
اكبرفهيمى، اكرم يرند، آرمين زارعيان.

$$
\text { تعارض مثافع }
$$

طبق نظر نويسند ان اين مقاله هيجگونه تعارض منافعى نداشئه

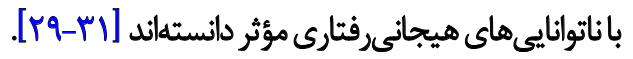
مطالعات محدودى نيز ارتباط جنسيت وخودتعيين گرى رابررسى

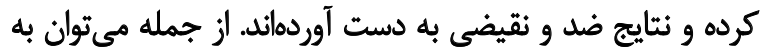

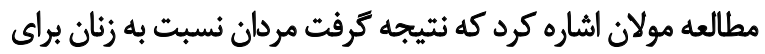

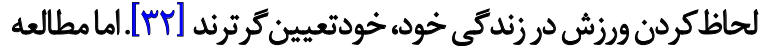

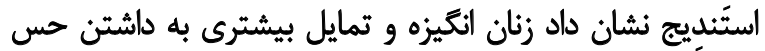

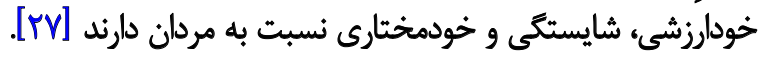

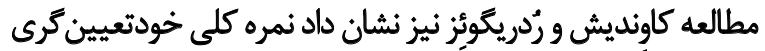

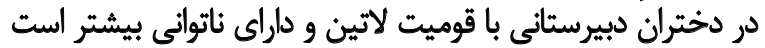

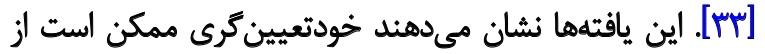

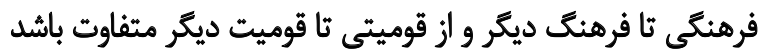

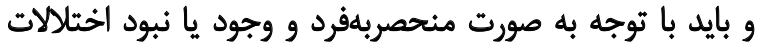

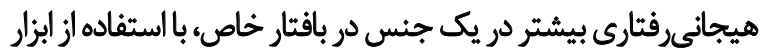

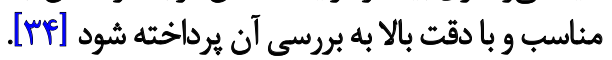

در يروهش حاضر، ضريب كودر ريجاردسون با مقدار 19 19.،

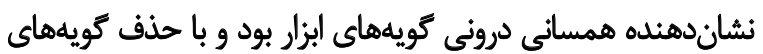

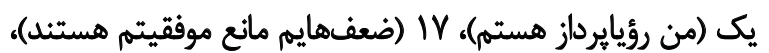

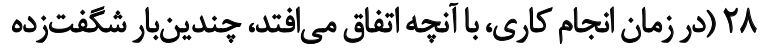

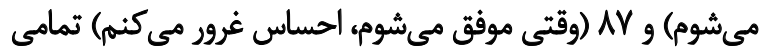

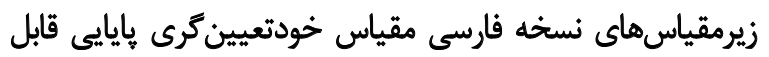

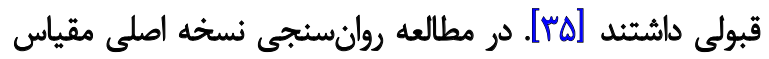

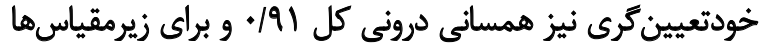

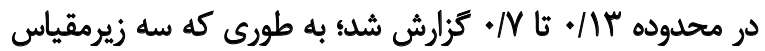

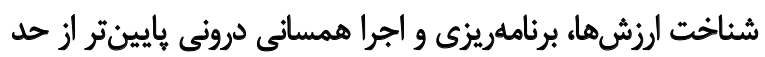

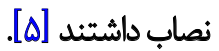

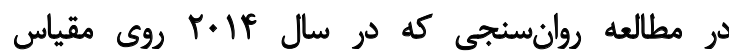

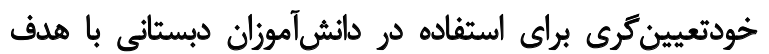

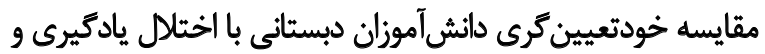

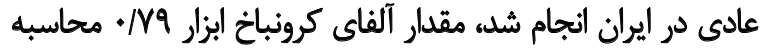

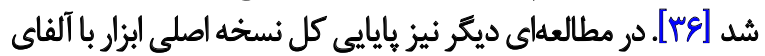

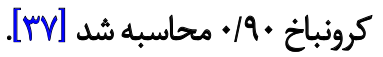

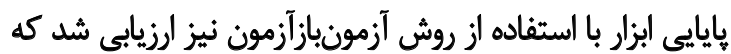

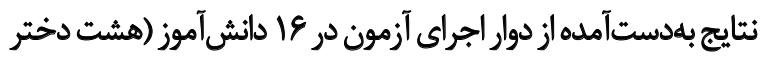

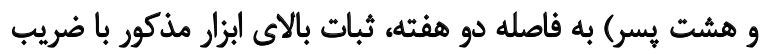

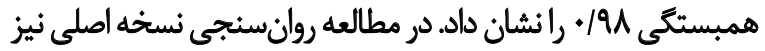

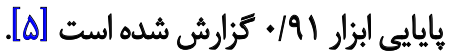

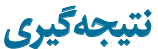

بر اساس يافتههاي اين مطالعه، نسخه فارسى مقياس

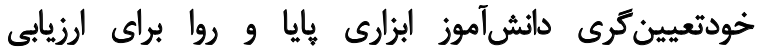

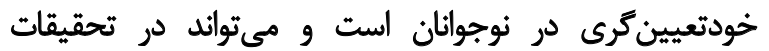

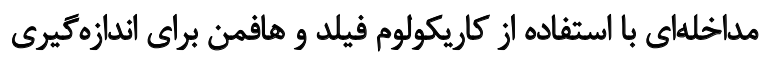




\section{References}

[1] Hui EK, Tsang SK. Self-determination as a psychological and positive youth development construct. The Scientific World Journal. 2012; 2012:759358. [DOI:10.1100/2012/759358] [PMID] [PMCID]

[2] Field S, Hoffman A, Posch M. Self-determination during adolescence a developmental perspective. Remedial and Special Education. 1997; 18(5):285-93. [DOI:10.1177/074193259701800504]

[3] Alamri M. Reliability and validity of an Arabic version of the SelfDetermination Assessment-internet (SDAi) [PhD. dissertation]. Detroit: Wayne State University; 2017.

[4] Deci EL, Ryan RM. Self-determination theory: A macrotheory of human motivation, development, and health. Canadian Psychology/Psychologie Canadienne. 2008; 49(3):182-5. [DOI:10.1037/ a0012801]

[5] Hoffman A, Field Sh, Sawilowsky Sh. Self-determination assessment battery. user's guide. New York: Center for Self-Determination and Transition; 2004.

[6] Wehmeyer ML, Palmer SB, Shogren K, Williams-Diehm K, Soukup $\mathrm{JH}$. Establishing a causal relationship between intervention to promote self-determination and enhanced student self-determination. The Journal of Special Education. 2013; 46(4):195-210. [DOI:10.1177/0022466910392377] [PMID] [PMCID]

[7] Hagiwara M, Shogren K, Leko M. Reviewing research on the selfdetermined learning model of instruction: mapping the terrain and charting a course to promote adoption and use. Advances in Neurodevelopmental Disorders. 2017; 1(1):3-13. [DOI:10.1007/ s41252-017-0007-7]

[8] Karvonen M, Test DW, Wood WM, Browder D, Algozzine B. Putting self-determination into practice. Exceptional Children. 2004; 71(1):23-41. [DOI:10.1177/001440290407100102]

[9] Chao PC, Chou YC. Elementary and junior high school teachers' promotion of self-determination in Taiwan. International Education Studies. 2017; 10(9):141-51. [DOI:10.5539/ies.v10n9p141]

[10] Shogren KA, Wehmeyer ML, Little TD, Forber-Pratt AJ, Palmer $\mathrm{SB}$, Seo H. Preliminary validity and reliability of scores on the selfdetermination inventory: Student report version. Career Development and Transition for Exceptional Individuals. 2017; 40(2):92103. [DOI:10.1177/2165143415594335]

[11] Chambers CR, Wehmeyer ML, Saito Y, Lida KM, Lee Y, Singh V. Self-determination: What do we know? Where do we go? Exceptionality. 2007; 15(1):3-15. [DOI:10.1080/09362830709336922]

[12] Wehmeyer ML. Student self-report measure of self-determination for students with cognitive disabilities. Education and Training in Mental Retardation and Developmental Disabilities. 1996; 31(4):282-93.

[13] Martin JE, Marshall, L. Choicemaker: A comprehensive self-determination transition program. Intervention in School and Clinic. 1995; 30(3):147-56. [DOI:10.1177/105345129503000304]

[14] Wolman JM, Campeau PL, DuBois PA, Mithaug DE, Stolarski VS. AIR self-determination scale and user guide. Washington, D.C: American Institute for Research; 1994.
[15] Field S, Hoffman A. Development of a model for self-determination. Career Development for Exceptional Individuals. 1994; 17(2):159-69. [DOI:10.1177/088572889401700205]

[16] Eke UP. A construct validation of self-determination instrument: Using adult substance abuse consumers in residential setting [PhD. dissertation]. Michigan: Wayne State University; 1996.

[17] Holt K. Reliability and validity of the Self-determination student scale with an adjudicated incarcerated delinquent population[PhD. dissertation]. Michigan: Wayne State University; 2006.

[18] Montazeri A, Goshtasebi A, Vahdaninia M, Gandek B. The Short Form health survey (SF-36): Translation and validation study of the Iranian version. Quality of Life Research. 2005; 14(3):875-82. [DOI:10.1007/s11136-004-1014-5] [PMID]

[19] Achenbach TM. Manual for the youth self-report and profile Burlington: University of Vermont; 1991.

[20] Kakaberaie K, Asgar-Abad M, Fedaei Z. [Validation of Achenbakh's behavioral problems: Performing the Youth Self-Report Scale (YSR) for 11-18 year-old adolescents on high school students (Persian)]. Journal of Research in Psychological Health. 2006; 1(4):50-66.

[21] Lawshe CH. A quantitative approach to content validity 1. Personnel Psychology. 1975; 28(4):563-75. [DOI:10.1111/j.1744-6570.1975.tb01393.x]

[22] Polit DF, Beck CT, Owen SV. Is the CVI an acceptable indicator of content validity? Appraisal and recommendations. Research in Nursing \& Health. 2007; 30(4):459-67. [DOI:10.1002/nur.20199] [PMID]

[23] Schneider Z. Nursing research: Methods, critical appraisal and utilisation. Maryland Heights: Mosby; 2003.

[24] Carter EW, Lane KL, Pierson MR, Glaeser B. Self-determination skills and opportunities of transition-age youth with emotional disturbance and learning disabilities. Exceptional Children. 2006; 72(3):333-46. [DOI:10.1177/001440290607200305]

[25] Carter EW, Lane KL, Crnobori M, Bruhn AL, Oakes WP. Self-determination interventions for students with and at risk for emotional and behavioral disorders: Mapping the knowledge base. Behavioral Disorders. 2011; 36(2):100-16. [DOI:10.1177/01987429110 3600202]

[26] Kelly JR, Shogren KA. The impact of teaching self-determination skills on the on-task and off-task behaviors of students with emotional and behavioral disorders. Journal of Emotional and Behavioral Disorders. 2014; 22(1):27-40. [DOI:10.1177/1063426612470515]

[27] Standage M, Duda JL, Ntoumanis N. A test of self-determination theory in school physical education. British Journal of Educational Psychology. 2005; 75(3):411-33. [DOI:10.1348/000709904X22359] [PMID]

[28] Cavendish W. The role of gender, race/ethnicity, and disability status on the relationship between student perceptions of school and family support and self-determination. Career Development and Transition for Exceptional Individuals. 2017; 40(2):113-22. [DOI:10.1177/2165143416629359] 
[29] Martin JE, Mithaug DE, Cox P, Peterson LY, Van Dycke JL, Cash ME. Increasing self-determination: Teaching students to plan, work, evaluate, and adjust. Exceptional Children. 2003; 69(4):43146. [DOI:10.1177/001440290306900403]

[30] Benitez DT, Lattimore J, Wehmeyer ML. Promoting the involvement of students with emotional and behavioral disorders in career and vocational planning and decision-making: The self-determined career development model. Behavioral Disorders. 2005; 30(4):431-47. [DOI:10.1177/019874290503 000401]

[31] Sczesniak E. An examination of a self-determination strategy on academic engagement for students with emotional support needs at risk of dropout [PhD dissertation]. Glenside, PA: Arcadia University; 2016.

[32] Mullan E, Markland D. Variations in self-determination across the stages of change for exercise in adults. Motivation and Emotion. 1997; 21(4):349-62. [DOI:10.1023/A:1024436423492]

[33] Rodriguez RJ, Cavendish W. Differences in the relationship between perceived family environments and self-determination among students with disabilities. International Journal for Research in Learning Disabilities. 2013; 1(2):110-34.

[34] Zolfaghari AR, Fathi D, Massah O. [Behavior disorders prevalence in high school students in Hamedan Province (Persian)]. Archives of Rehabilitation. 2014; 15(1):45-52.

[35] Hair JF, Black WC, Babin BJ, Anderson RE. Multivariate data analysis. London: Pearson; 2010.

[36] Yailagh MS, Abbasi M, Behrozi N, Alipour S, Yakhchali $\mathrm{AH}$. Comparisons of self-determination among students with learning disabilities and without learning disabilities. American Journal of Applied Psychology. 2014; 3(2):27-31. [DOI:10.11648/j.ajap.20140302.11]

[37] Licardo $M$, Schmidt M. Why is self-determination important for students with and without disabilities in vocational education? The New Educational Review. 2016; 46:200-10. [DOI:10.15804/tner.2016.46.4.17]

[38] Sajadi H, Zanjari N. [Disability in Iran: Prevalence, characteriscs and socio-economic correlates (Persian)]. Rehabilitation. 2015; 16(1):36-47. 